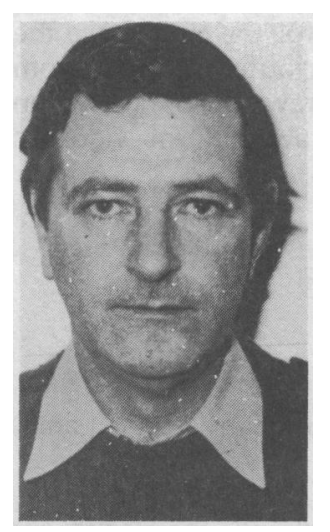

T. A. I. Bouchier-Hayes

\section{SULINDAC VERSUS IBUPROFEN IN SPRAINS AND STRAINS}

\author{
Lt. CoI. T. BOUCHIER HAYES, FRCGP, DRCOG, RAMC* \\ Capt. A. FYVIE, MB, BS, RAMC* , P. G. JANKE, MRCP† \\ M. J. VANDENBURG, BSc, MRCPt and W. J, C. CURRIE, MD, MIBiol. $t$ \\ ${ }^{*}$ Royal Military Academy Hospital, Sandhurst \\ tClinical Research Department, Merck Sharp \& Dohme Limited, Hertford Road \\ Hoddesdon, Herts.
}

In a double:blind parallel group randomised study 191 patients with acute sprains and strains of ankle, hip, shoulder or knees were treated with either $400 \mathrm{mg}$ sulindac or $1200 \mathrm{mg}$ ibuprofen per day for 4 days; of these, 176 completed the trial. Spontaneous pain (day and night), pain on active movement, swelling and tenderness were assessed before and after the treatment period along with a physician's and patient's assessment of therapy at the end of the study. The vast majority of patients had a successful outcome whichever treatment they were taking. No patients reported any adverse effect during the study.

\section{INTRODUCTION}

Sulindac, a derivative of an indene acetic acid (indomethacin is an indole-acetic acid derivative), is a relatively new non-steroidal anti-inflammatory drug (NSAID). Its actions, characteristic for this group, include analgesia, anti-inflammatory and antipyretic activity. Sprain and strain injuries undoubtedly have an inflammatory component during the acute phase and logically lend themselves to treatment with NSAIDs in the hope of bringing about rapid relief of pain and inflammation and consequently improved function. Ibuprofen a nonsteroidal anti-inflammatory drug has been shown to be effective in such cases as Muckle (1974); sulindac, however, has never been assessed in this area. It was therefore decided to study the relative merits of sulindac and ibuprofen in the treatment of sprains and strains, when used in clinical practice as an adjunct to conventional physical therapy. Most soft tissue injuries in the UK are seen and treated by family physicians and/or Accident and Emergency Departments. A large study in patients from general practice would require the cooperation of many general practitioners. This obviously introduces the inherent problems of multi-observers (Grayson, 1977) in clinical trials even if they are all

\footnotetext{
*Present address:

Lt. Col. T. Bouchier Hayes,

Army Medical Reception Station,

Circular Road South,

COLCHESTER,

Essex.
}

following a standard rigid protocol. Similar and more difficult problems could occur in Accident and Emergency Departments, where the likelihood of initial and follow-up examinations by the same officer is extremely remote. These problems could be overcome with a study centred on a practice likely to present a large volume of acute soft tissue injuries to a single observer. The Royal Military Academy Hospital at Sandhurst incorporates such a practice.

\section{PATIENTS AND METHODS}

Males over the age of 18 years with a diagnosis of acute unilateral sprains or strains of the ankle, hips, shoulders or knees based upon history and physical findings, who presented themselves to the Royal Military Academy Hospital at Sandhurst within $\mathbf{4 8}$ hours of onset were considered eligible for the study. Patients were excluded if they had only mild pain at the first examination, fracture or suspicion of fracture subsequently confirmed by X-ray, of any contraindication to the use of either drug as stated in the data sheets.

Patients satisfying the entry criteria were allocated, using a predetermined randomised schedule, to receive either sulindac (Clinoril) $200 \mathrm{mg}$ twice daily or ibuprofen (Brufen) $\mathbf{4 0 0} \mathrm{mg}$ three times daily for a period of 4 days. No concomitant anti-inflammatory agent or treatments other than those shown in Table I were permitted during the trial period.

At entry and after days 1 and 4 of the trial the 
TABLE I

Other treatment used during trial. $\mathbf{N}=176$

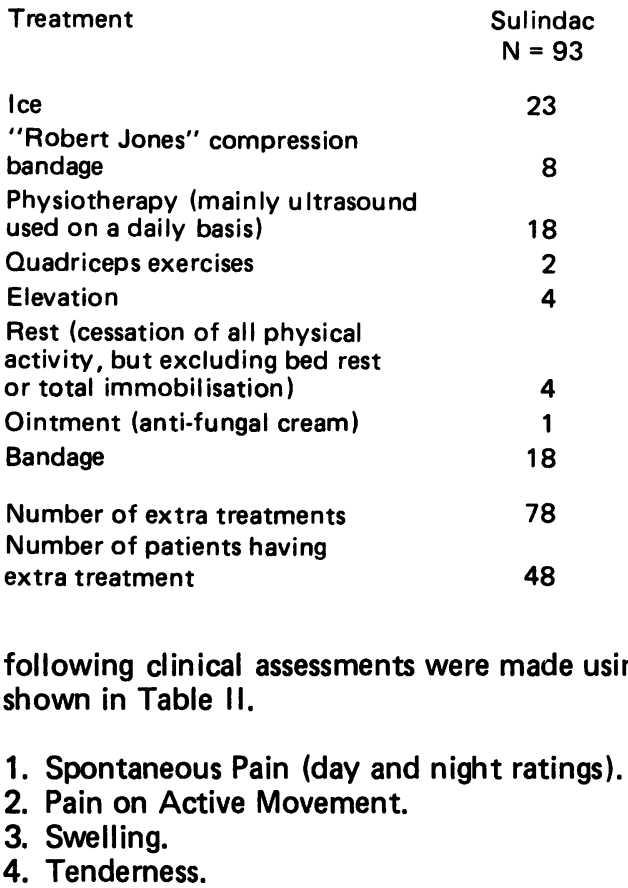

An overall evaluation of response to treatment was made by both physician and patient at the end of the 4 day study period according to the rating scales included in Table II. Adverse effects were monitored during the study.

\section{RESULTS}

A total of 176 patients, 93 of whom took sulindac and 83 who took ibuprofen, were included in the analysis. Initially 191 patients entered into the study; 96 of whom received sulindac and 95 ibuprofen, however, 15 patients were omitted subsequently from the analysis because of either protocol violation or failure to attend for reassessment.

The initial characteristics of the patients allocated to the two treatment groups are shown in Tables III and IV. The group taking sulindac tended to have a higher proportion of knee injuries in it than the group taking ibuprofen. Otherwise, the groups were reasonably balanced.

The measure of efficacy of the two treatments has been taken as the difference between the assessment scores immediately prior to starting medication, and those recorded on the final (4th) day of the study period.

\section{TABLE II}

Rating scales.

B. Pain on Active Movement

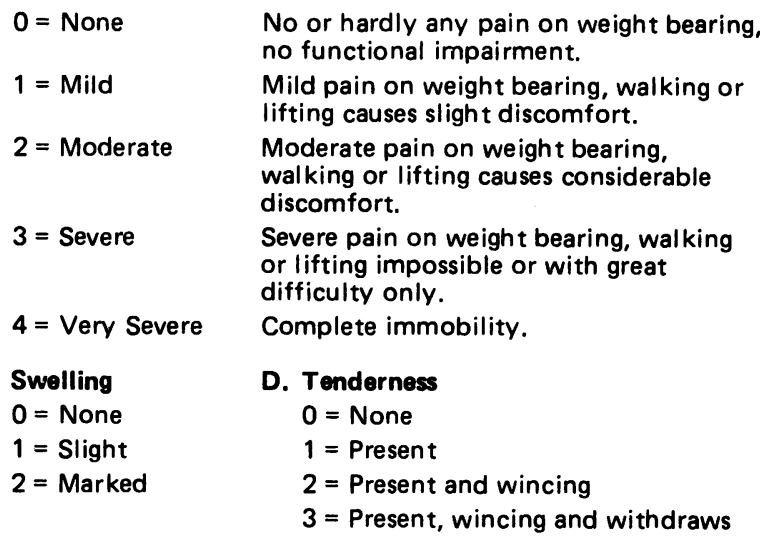

E. Patient's and Investigator's Overall Evaluation of Treatment Efficacy

$0=$ Poor None or hardly any effect.

1 = Slight Some effect, but could be better.

2 = Fair

$3=$ Good

$4=$ Excellent

Satisfactory effect.

Good but not perfect.

Ideal, best possible effect.

TABLE III

\section{Comparison of sulindac and ibuprofen at initial} assessment.

\begin{tabular}{|c|c|c|c|}
\hline & & $\begin{array}{c}\text { Sulindac } \\
N=93\end{array}$ & $\begin{array}{c}\text { Ibuprofen } \\
N=83\end{array}$ \\
\hline \multirow[t]{4}{*}{ Injury } & Knee & 48 & 83 \\
\hline & Ankle & 38 & 39 \\
\hline & Hips & 3 & 7 \\
\hline & Other & 4 & 4 \\
\hline \multirow[t]{2}{*}{ Age } & Mean & $* 22.0$ & $* * 21.2$ \\
\hline & Standard Deviation & 6.5 & 5.4 \\
\hline \multirow[t]{4}{*}{ Side } & Left & 37 & 32 \\
\hline & Right & 52 & 50 \\
\hline & Both & 1 & 0 \\
\hline & Not recorded & 3 & 1 \\
\hline \multirow{3}{*}{$\begin{array}{l}\text { Hours after } \\
\text { Trauma }\end{array}$} & Mean & 21.8 & 20.7 \\
\hline & Standard Deviation & 14.1 & 13.3 \\
\hline & Not recorded & 1 & 0 \\
\hline
\end{tabular}


Table $V$ shows, for each efficacy parameter, the distribution of changes in the groups. A positive score is an improvement, a negative score is a deterioration. Thus, it can be seen that the majority of patients achieved a favourable response irrespective of which treatment was taken. A between-treatment comparison showed no significant difference ( $>.05$ ) in all cases (Mann-Whitney U-test). The mean rankings (Table VI) show that preference is divided equally between the two drugs over the different measures of efficacy. The improvement score is reflected in both the patient's and physician's overall evaluation of treatment (Table VII and VIII).

\section{TABLE IV}

\section{Comparison of sulindac and ibuprofen at initial assessment.}

\begin{tabular}{|c|c|c|c|c|c|c|c|}
\hline & & & & Score & & & \\
\hline & 0 & 1 & 2 & 3 & 4 & N/R & N/A \\
\hline Day Pain & & & & & & & \\
\hline Sulindac & 30 & 31 & 24 & 8 & 0 & & \\
\hline Ibuprofen & 30 & 16 & 31 & 5 & 1 & & \\
\hline Night Pain & & & & & & & \\
\hline Sulindac & 43 & 22 & 8 & 5 & 0 & 4 & 11 \\
\hline Ibuprofen & 38 & 14 & 17 & 2 & 0 & 1 & 11 \\
\hline Active Mot & & & & & & & \\
\hline Sulindac & 0 & 12 & 51 & 29 & 1 & & \\
\hline Ibuprofen & 0 & 9 & 41 & 32 & 1 & & \\
\hline Tenderness & & & & & & & \\
\hline Sulindac & 3 & 29 & 33 & 28 & 0 & & \\
\hline Ibuprofen & 6 & 24 & 31 & 22 & 0 & & \\
\hline Swelling & & & & & & & \\
\hline Sulindac & 40 & 29 & 22 & 2 & 0 & & \\
\hline Ibuprofen & 35 & 24 & 18 & 5 & 0 & 1 & \\
\hline
\end{tabular}

N/R Not recorded

N/A Not applicable

Taking a fair, good or excellent effect as meaning a successful outcome then 72 of $93(77 \%)$ patients taking sulindac judged themselves to have been treated successfully compared with 71 of $83(85 \%)$ taking ibuprofen. In the view of the investigator the corresponding results were 68 (73\%) successfully treated with sulindac compared with $61(73 \%)$ of those on ibuprofen. No side effects were reported in the study.

\section{DISCUSSION}

This large study has shown that non-steroidal antiinflammatory agents can be used beneficially as an adjunct to physical therapies in acute soft tissue injuries. In this particular study sulindac and ibuprofen proved to be equally beneficial. Of interest is the absence of any

\section{TABLE V}

Change in scores between Day 0 and Day 4.

$$
\begin{aligned}
& \text { Change in Score } \\
& +4+3+2+1 \quad 0 \quad-1 \quad-2 \quad \text { N/R N/A }
\end{aligned}
$$

\begin{tabular}{|c|c|c|c|c|c|c|c|c|c|}
\hline Sulindac & 0 & 2 & 21 & 32 & 38 & & & & \\
\hline Ibuprofen & 1 & 1 & 29 & 17 & 33 & 2 & & & \\
\hline \multicolumn{10}{|l|}{ Night Pain } \\
\hline Sulindac & 0 & 3 & 7 & 22 & 45 & 1 & & 4 & 11 \\
\hline Ibuprofen & 0 & 0 & 17 & 14 & 40 & 0 & & 1 & 11 \\
\hline \multicolumn{9}{|c|}{ Active Motion } & \\
\hline Sulindac & 1 & 11 & 25 & 35 & 19 & 1 & & 1 & \\
\hline Ibuprofen & 0 & 6 & 28 & 32 & 16 & 1 & & & \\
\hline \multicolumn{9}{|l|}{ Tenderness } & \\
\hline Sulindac & 0 & 8 & 25 & 37 & 21 & 2 & & & \\
\hline Ibuprofen & 0 & 4 & 19 & 38 & 20 & 2 & & & \\
\hline \multicolumn{9}{|c|}{ Range of Movement } & \\
\hline Sulindac & 0 & 4 & 13 & 17 & 57 & 0 & 1 & 1 & \\
\hline Ibuprofen & 0 & 1 & 22 & 18 & 40 & 2 & & & \\
\hline \multicolumn{9}{|l|}{ Swelling } & \\
\hline Sulindac & 0 & 1 & 10 & 33 & 45 & 2 & 1 & 1 & \\
\hline Ibuprofen & 0 & 0 & 9 & 27 & 45 & 1 & & 1 & \\
\hline
\end{tabular}

Day Pain

N/R Not recorded

N/A Not applicable

adverse reactions reported by the patients taking either of the two therapies. This might be explained by two considerations. First the treatment period was relatively short and any adverse reactions may not have manifested themselves by the end of the trial and second, the population studied was a very selective one of young, fit, military personnel who presumably have a high "complaint" threshold and are highly motivated to return to active duty. There are, at any one time, approximately 700 officer cadets/student officers undergoing military training at the Royal Military Academy, Sandhurst. In general they are young, fit personnel who are required to participate in vigorous training and sporting activities. It is important that loss of time from training is minimised and therefore the object in treating any sporting/ training injury is to return the subject to full duties as quickly as possible. This has been achieved by immediate first-aid, open access to medical opinion, the use of local supportive measures and physiotherapy and the administration of anti-inflammatory drugs. The authors recognise the contribution of "standard" treatments such as ice and compression to the relief of early pain, and thus to the overall responses of the patients receiving such concurrent therapy. A comparison between standard and anti-inflammatory treatment is currently being carried out in a different study.

In conclusion this study has demonstrated that sulindac has a place in the treatment of acute sprains and strains. 
TABLE VI

$$
\text { Mean Rank }
$$

No. of

Patients
TABLE VII

P.Values
Day Pain

Sulindac

Ibuprofen

Night Pain

Sulindac

Ibuprofen

Active Motion

Sulindac

Ibuprofen

Tenderness

Sulindac

Ibuprofen

Range of Movement

Sulindac

Ibuprofen

Swelling

Sulindac

Ibuprofen

$\begin{array}{ll}86.3 & 93 \\ 91.0^{*} & 93 \\ & \\ 72.6 & 78 \\ 77.6^{*} & 71\end{array}$

88.5*

87.4

$91.7^{*}$

84.9

83.2

93.3*

88. $7^{*}$

86.2

92

83

93

83

92

83

92

82

\section{3}

3

8

N.S

N.S.

N.S.

N.S.

N.S.

N.S.

Sulindac

Ibuprofen

Patients' evaluation of treatment efficacy.

\begin{tabular}{|c|c|c|c|c|c|c|}
\hline & \multicolumn{6}{|c|}{ Score } \\
\hline & 0 & 1 & 2 & 3 & 4 & $N / R$ \\
\hline Sulindac & 2 & 15 & 15 & 40 & 17 & 4 \\
\hline Ibuprofen & 4 & 6 & 19 & 40 & 12 & 2 \\
\hline
\end{tabular}

* Indicates group with higher mean rank, i.e. group with better performance.

\section{TABLE VIII}

Investigators' evaluation of treatment efficacy.

\begin{tabular}{lcccccc} 
& \multicolumn{7}{c}{ Score } \\
& 0 & 1 & 2 & 3 & 4 & N/R \\
Sulindac & 7 & 13 & 21 & 47 & 0 & 5 \\
Ibuprofen & 6 & 14 & 24 & 37 & 0 & 2
\end{tabular}

\section{REFERENCES}

Grayson, M. F., 1977 “International co-ordination of drug trials". Eular Bulletin, Monograph 1, Eular Publ., Basel.

Muckle, D. S., 1974 "Comparative study of ibuprofen and aspirin in soft tissue injuries". Rheumatology and Rehabilitation 13: 141-147.

\section{BASIC ORIENTATION COURSE IN SPORTS MEDICINE \\ Organised by the British Association of Sport and Medicine Scottish Area on behalf of the International Federation of Sports Medicine (F.I.M.S.)}

Monday, 3rd September-Friday 7th, 1984, at Jordanhill College, Southbrae Drive, GLASGOW. The syllabus covers the requirements of the basic course, specified by F.I.M.S., and doctors attending the full course are eligible for Associate Membership of F.I.M.S. Subjects include the physiology of exercise, training, medical management of teams, acute trauma, especially soft tissue injuries, overuse injuries, cardiology, diet and problems of doping. Problems of sport for the middle aged, elderly, children and women are also included. Recent legislation regarding Section 63 reimbursement for general practitioners may cause difficulties, especially for those travelling over 100 miles, so GPs are advised to contact their local FPCs well in advance, bearing in mind that this is the ONLY such course being run anywhere in the U.K., and that the syllabus is not only specific to medicine in sport, but also to general medicine, gynaecology, ENT, and traumatology, and is therefore a good general revision course for all those in general and hospital practice. Physiotherapists and sports scientists are also eligible to attend. The tuition fee is $\mathbf{1 2 5}$, and full board and accommodation is available in College for $\mathbf{f 1 2 5}$. Applications and enquiries to:

FIMS/BASM Course,

Further Education Department, Jordanhill College,

Southbrae Drive,

GLASGOW 